\title{
Mitral annular plane systolic excursion and intra-myocardial haemorrhage in acute myocardial infarction
}

Pankaj Garg*, Ananth Kidambi, David P Ripley, Laura E Dobson, Peter P Swoboda, Tarique A Musa, Bara Erhayiem, Adam K McDiarmid, John P Greenwood, Sven Plein

From 18th Annual SCMR Scientific Sessions

Nice, France. 4-7 February 2015

\section{Background}

Mitral annular plane systolic excursion (MAPSE) is known to have prognostic importance in the risk stratification of patients with acute myocardial infarction (MI). In post-MI patients with MAPSE $<8 \mathrm{~mm}$, the combined mortality and hospitalization incidence is $43.8 \%$. Similarly, CMR studies have shown that intra-myocardial haemorrhage (IMH) in the infarct core is an independent marker of prognosis. We hypothesised that the MAPSE on 4-chamber cineCMR is correlated to left ventricular ejection fraction (EF) and to the presence of IMH.

\section{Methods}

Fourty-four patients received CMR examination at 3T (Intera CV, Philips Healthcare, Best, The Netherlands) within 3 days following reperfused ST-elevation acute MI. Cine, T2-weighted, T2* imaging and LGE imaging $(0.1 \mathrm{mmol} / \mathrm{kg}$ gadolinium DTPA) were performed. Infarct and microvascular obstruction (MO) extent were measured from late gadolinium enhancement (LGE) images. The presence and extent of IMH was investigated by combined analysis of $\mathrm{T} 2 \mathrm{w}$ and $\mathrm{T} 2 *$ sequences. We computed MAPSE (medial, lateral and average) using the 4-chamber cine. A line was drawn across both the medial and lateral mitral annulus as a reference point in end-diastole (just after closure of mitral valve). A second reference line was drawn across the same plane on an image taken just after closure of the aortic valve. The longitudinal distance parallel to the left ventricular wall was measured for both medial and lateral walls (Figure 1).

\section{Multidisciplinary Cardiovascular Research Centre \& The Division of} Cardiovascular and Diabetes Research, Leeds Institute of Genetics, Health \& Therapeutics, University of Leeds, Leeds, UK

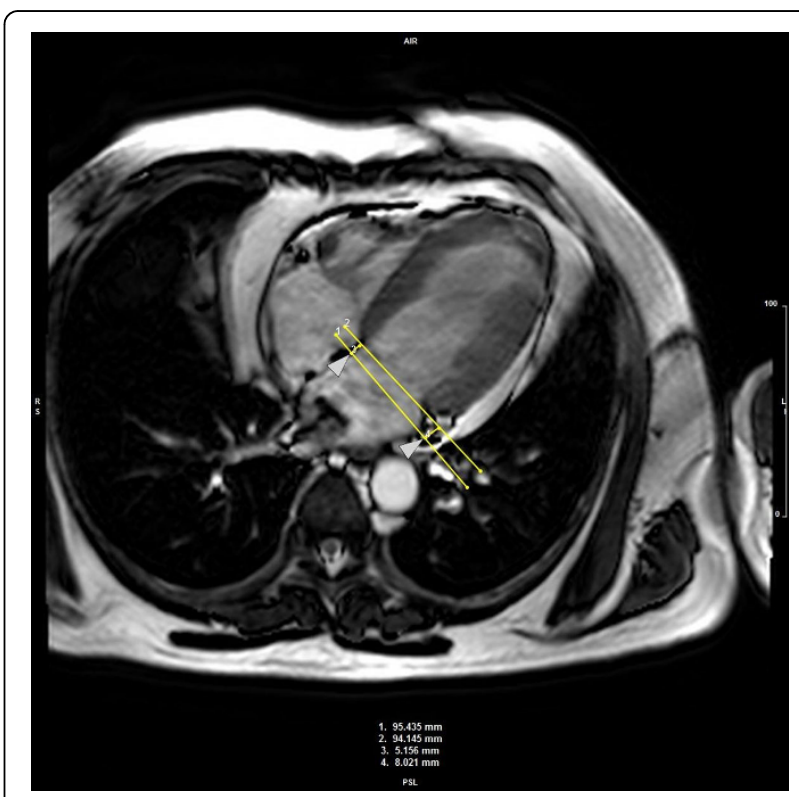

Figure 1 Illustration to show how the MAPSE measurements were taken in the four-chamber cine using contour forwarding.

\section{Results}

Of the 44 patients, 37 (84\%) were male. Mean age of our studied population was $58.27 \pm 11.41$. CMR parameters were as follows: LVEF $48.2 \pm 11.4 \%$; indexed left ventricular end-diastolic volume (LVEDVi) $82.4 \pm 15.7 \mathrm{ml} / \mathrm{m} 2$; infarct volume LGE of $15.5 \pm 12.2 \mathrm{ml}$; medial MAPSE of $9.8 \pm 2.9 \mathrm{~mm}$; lateral MAPSE of $10.97 \pm 2.3 \mathrm{~mm}$ and averaged MAPSE of $10.27 \pm 2.1 \mathrm{~mm}$. Lateral MAPSE was significantly reduced to previously studied age-adjusted normal values $(12.8 \pm 2.2 \mathrm{~mm}$; $\mathrm{p}=0.0087)(1)$.Controlling for age/gender/hypertension/hypercholesterolemia/ 

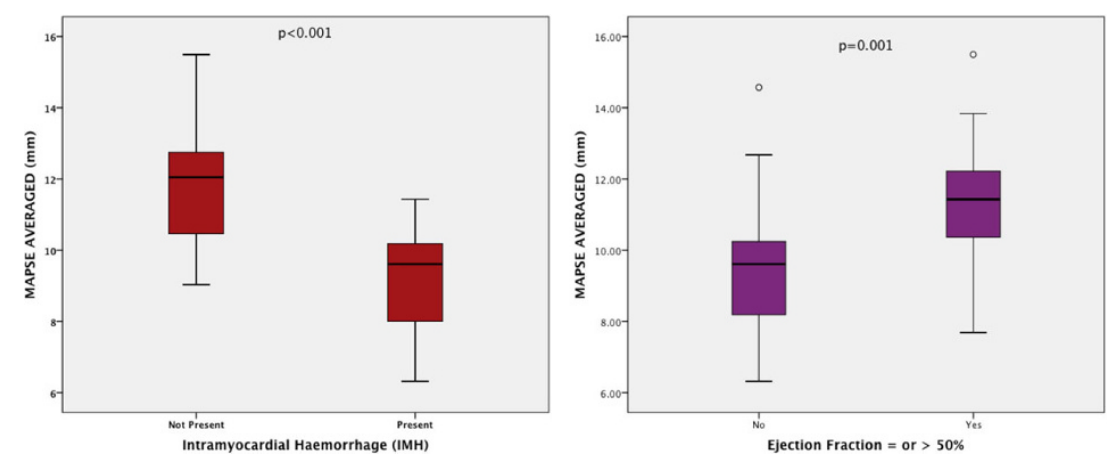

Figure 2 Box-plot of averaged-MAPSE to IMH and EF.

smoker/diabetes, IMH was strongly negatively correlated to average MAPSE $(\mathrm{r}=-0.65 ; \mathrm{p}<0.001)$. Averaged MAPSE was also moderately correlated to LVEF $(r=0.47$; $\mathrm{p}=0.001$ ) (Figure 2). A cut-off value of $11 \mathrm{~mm}$ for averaged MAPSE is $96 \%$ sensitive and $68.4 \%$ specific in ruling out $\mathrm{IMH}$.

\section{Conclusions}

Averaged MAPSE, which is a simple CMR derived parameter of longitudinal function, has the potential to predict the presence of IMH in the setting of re-perfused acute myocardial infarction. This parameter could be easily measured at bedside by transthoracic echocardiography to predict presence of IMH.

\section{Funding}

JPG and SP receive a research grant from Philips Healthcare. SP is funded by British Heart Foundation fellowship (FS/10/62/28409).

Published: 3 February 2015

\section{Reference}

1. Bulluck $H$, Ngamkasem $H$, Sado D, et al: A simple technique to measure TAPSE and MAPSE on CMR and normal values. J Cardiovasc Magn Reson 2014, 16(Suppl 1):P22.

doi:10.1186/1532-429X-17-S1-P163

Cite this article as: Garg et al:: Mitral annular plane systolic excursion and intra-myocardial haemorrhage in acute myocardial infarction. Journal of Cardiovascular Magnetic Resonance 2015 17(Suppl 1):P163.
Submit your next manuscript to BioMed Central and take full advantage of:

- Convenient online submission

- Thorough peer review

- No space constraints or color figure charges

- Immediate publication on acceptance

- Inclusion in PubMed, CAS, Scopus and Google Scholar

- Research which is freely available for redistribution

Submit your manuscript at www.biomedcentral.com/submit
C BioMed Central 